\title{
Risk and Outcome of Secondary Primary Malignancies After Radioactive lodine Treatment in Differentiated Thyroid Cancer Patients
}

\author{
Xiaoran Mei \\ Xin Hua Hospital Affiliated to Shanghai Jiao Tong University School of Medicine \\ Xiaoqin Yao \\ The Affiliated Yantai Yuhuangding Hospital of Qingdao University \\ Fang Feng \\ Xin Hua Hospital Affiliated to Shanghai Jiao Tong University School of Medicine \\ Hui Wang \\ Xin Hua Hospital Affiliated to Shanghai Jiao Tong University School of Medicine \\ Weiwei Cheng ( $\sim$ wcheng37@outlook.com) \\ Xin Hua Hospital Affiliated to Shanghai Jiao Tong University School of Medicine
}

\section{Research Article}

Keywords: radioactive iodine, secondary primary malignancies, differentiated thyroid cancer

Posted Date: January 18th, 2021

DOI: https://doi.org/10.21203/rs.3.rs-137480/v1

License: @ (1) This work is licensed under a Creative Commons Attribution 4.0 International License. Read Full License 


\section{Abstract}

Background To investigate the relative risks(RRs) of secondary primary malignancies (SPMs) by different sites associated with radioactive iodine (RAI) treatment in differentiated thyroid cancer (DTC) survivors, and the attributable risk proportion of RAl treatment for developing different SPMs. We identified DTC survivors from SEER registries and performed Poisson regression to calculate the RRs of SPMs by different sites associated with RAI treatment, as well as the attributable risk of RAI for different SPMs.

Results The RRs of developing SPM associated with RAI varied from 0.86 (0.53-1.40) for SPMs of nervous system to 1.25 (1.05-1.50) for hematologic SPMs. The RRs of developing all cancer combined SPMs generally increased with age at DTC diagnosis and decreased with the latency time. We estimated that the attributable risk proportion of RAI treatment is only $0.9 \%$ for all cancer combined SPMs and $20 \%$ for hematologic SPMs, which is the highest among all SPMs. The tumor features and mortality of patients treated with and without RAI are generally comparable.

Conclusion The RR of developing SPMs associated with RAI treatment in DTC survivors increase only in hematologic systems, with the highest attributable risk proportion of RAI treatment among all cancer combined SPMs. However, in consideration of its low incidence in all DTC survivors, the absolute number of hematologic SPMs would be low. For all cancer combined SPMs in DTC survivors, a very low proportion is associated with RAI treatment, indicating patients and physicians should not be panicked with the RAI treatment in DTC patients.

\section{Introduction}

Differentiated thyroid cancer (DTC) is the most prevalent endocrine cancer and the incidence of DTC has increased dramatically worldwide in the past few decades $^{1-2}$. Generally, DTC patients have a favorable prognosis after appropriate treatment, with the 10 -year survival rate estimated to be greater than $90 \%{ }^{3-}$ ${ }^{4}$. Given the rising incidence and the good prognosis of DTC, the development of a second primary malignancy (SPM) became an important concern for DTC survivors and also physicians ${ }^{5-7}$. It has been reported that DTC survivors have an $10 \%-30 \%$ higher risk of developing a SPM, comparing with the general population $^{5-8}$. These greater risks are probably a result of the combination of lifestyle, environment, genetic factors and the medical treatment for DTC.

Radioactive iodine (RAl) is commonly used in the treatment of DTC patients ${ }^{9}$. National Thyroid Cancer Treatment Co-operative Group reporting that $62-75 \%$ of individuals received RAI during their thyroid cancer treatment ${ }^{10}$. While most studies reported RAl treatment is associated with an increased risk of SPMs development in DTC survivors ${ }^{5-8}$, there are some suggesting a minor effect of RAl in inducing SPMs ${ }^{11-12}$. Analyses basing on all adult cancer survivors have indicated that most SPMs are actually developed due to non-radiation factors, such as lifestyle or genetics, and concluded that a small proportion of SPMs (< $10 \%)$ might be truly related to radiotherapy ${ }^{13-14}$. Although a lot of studies have investigated the risks of SPMs in DTCs survivors, none of them regarding the attributable risk of RAl treatment in inducing SPMs. Moreover, very few studies compared the biological features of SPMs in RAI treated and non-RAI treated DTCs survivors, as well as the clinical outcome of the two groups of patients.

Therefore, by using data from the SEER registries, we systemically investigated what proportion of SPMs might be induced by RAI treatment in DTC survivors in this study, and also compared the biological features of SPMs and the clinical outcome of RAI treated and non-RAI treated DTC survivors.

\section{Methods}

\section{Data Source and Participants}

The cohort was assembled using the April 2020 release of all 18 registries of the SEER database which covered approximately $28 \%$ of the US population. Patients aged 20 years or older who were diagnosed with a first primary thyroid cancer of papillary or follicular type between $2000-2016$ (the histological subtypes included in analysis were ICD codes 8050, 8260, 8290, 8330-8332, 8335, 8340-8344 and 8350) were identified by the SEER program statistical analysis software (SEER*Stat, version 8.3.6). As there is a lag time between radiation exposure and SPM development, we exclude patients whose follow-up time less than 24 months after their diagnosis of thyroid cancer. This criterion also ensured that we eliminated the surveillance bias that might result when patients who received RAI treatment were monitored more intensive than other patients in the first 24 months. Our study did not need ethics committee approval because the data are publicly available.

\section{Procedures and Statistical analysis}

The SEER ${ }^{\star}$ Stat MP-SIR (Multiple Primary-Standardized Incidence Ratio) tool was used to extract the details of all included RAI treated and non-RAI treated DTC survivors. We used Poisson regression analysis to estimate the relative risk (RR) with $95 \%$ Cls and P values of SPMs in DTCs survivors who received RAI compared with those who did not. The RRs were estimated for all combined SPMs and also for different SPMs by their sites, and further adjusted with age at DTC diagnosis, gender and year of DTC diagnosis. The RRs were also estimated in subgroup patients stratified according to their gender, age at DTC diagnosis and latency time from DTC diagnosis to SPM diagnosis. We estimated the number of excess SPMs related to RAI treatment by taking the number of SPMs in those treated with RAI minus the estimated number of SPMs in these patients if they have not treated with RAl. Attributable risks are also assessed for different SPMs by their sites, which quantify the risk in RAI treated DTC survivors that is attributable to RAI treatment.

The statistical analysis was performed similarly as our previous work ${ }^{15}$. To be specific, categorical data were summarized as frequencies and percentages while continuous data were summarized as medians and interquartile ranges (IQR). The Chi-Squared Test was used to analyze categorical variables while Wilcoxon-Mann-Whitney test was used to analyze continuous variables. All statistical analyses were performed using SPSS (version 22). Statistical significance was defined as a $P$ value of less than 0.05 , all statistical tests were two sided. 


\section{Results}

\section{Patient Characteristics}

We identified 104,026 patients with DTC from the SEER database in total, 51,212(49.2\%) patients received RAI as part of their DTC treatment while $52,814(50.8 \%)$ patients did not. Basic demographic and disease characteristics of these DTC patients are shown in Table 1. RAI treated DTC patients tend to have lower percentage of females, younger age, and high stage of tumors.

Table 1

Characteristics of patients with differentiated thyroid cancer enrolled in this study.

\begin{tabular}{|c|c|c|c|}
\hline & +RAl & -RAl & $P$ value \\
\hline No. of patients, $n$ & 51212 & 52814 & \\
\hline Patients with SPMs, $n(\%)$ & $2289(4.5 \%)$ & $2339(4.4 \%)$ & 0.752 \\
\hline Gender & & & $<0.001$ \\
\hline Female & 38941 & 42423 & \\
\hline Male & 12271 & 10391 & \\
\hline Median age at diagnosis of thyroid cancer (IQR), yrs & $46(36-56)$ & $49(38-59)$ & $<0.001$ \\
\hline Race & & & $<0.001$ \\
\hline White & 41771 & 42949 & \\
\hline Black & 2944 & 3983 & \\
\hline Asian and Pacific Islander & 5825 & 4816 & \\
\hline American Indian/Alaska native & 275 & 232 & \\
\hline Unknown & 397 & 834 & \\
\hline Stage & & & $<0.001$ \\
\hline Localized & $29943(58.5 \%)$ & $43872(83.1 \%)$ & \\
\hline Regional & 19304(37.7\%) & $6987(13.2 \%)$ & \\
\hline Distant & $1650(3.2 \%)$ & $635(1.2 \%)$ & \\
\hline Unknown/unstaged & $315(0.6 \%)$ & $1320(2.5 \%)$ & \\
\hline Median follow-up time (IQR), months & $91(57-133)$ & $85(52-130)$ & $<0.001$ \\
\hline
\end{tabular}

During the follow-up period (2000-2016), a total of 4,628 (4.4\%) DTC survivors developed SPMs, 2,289 patients have received RAI treatment (RAl+) and 2,339 patients have not (RAI-). The incidences of all cancer combined SPMs in RAI + and RAI- DTC survivors were $4.5 \%$ versus $4.4 \%$, showing no difference $(P=$ 0.752). Breast cancer is the most common SPM in all DTC survivors (1.1\%) while the lowest incidence of SPMs are cancers of nervous system and oral cavity and pharynx system (0.1\%) (Table S1). The spectrum of different SPMs was highly overlapped between the two groups (Figure S1). Exceptions were cancers of digestive and hematologic system, for which SPMs of digestive system accounts for a lower percentage (13.9\% vs $15.2 \%, P=0.216)$ and SPMs of hematologic system accounts for a higher percentage $(11.4 \%$ vs $9.2 \%, P<0.05)$ in RAl + group, as compared to RAl- group. The descriptive statistics of different SPMs in RAI + and RAl- patients are listed in Table 2. 
Table 2

Descriptive statistics of the SPMs in DTC survivors by their treatment.

\begin{tabular}{|c|c|c|c|c|c|c|c|c|c|c|c|c|c|}
\hline & \multicolumn{2}{|c|}{$\begin{array}{l}\text { Number of } \\
\text { patients, } n(\%)\end{array}$} & \multicolumn{2}{|c|}{$\begin{array}{l}\text { Number of } \\
\text { Females, } n(\%)\end{array}$} & \multicolumn{2}{|c|}{$\begin{array}{l}\text { Proportion of patients by } \\
\text { race(W/B/API) }\end{array}$} & \multicolumn{2}{|c|}{$\begin{array}{l}\text { Proportion of patients by } \\
\text { disease stage } \\
\text { (Local/Regional/Distant) }\end{array}$} & \multicolumn{2}{|c|}{$\begin{array}{l}\text { Median } \\
\text { age at } \\
\text { diagnosis } \\
\text { of the } \\
\text { SPMs, yrs }\end{array}$} & \multicolumn{2}{|c|}{$\begin{array}{l}\text { Median } \\
\text { follow-up } \\
\text { time since the } \\
\text { diagnosis of } \\
\text { SPMs,months }\end{array}$} & \multirow{2}{*}{$\begin{array}{l}\begin{array}{c}\text { Medii } \\
\text { laten } \\
\text { time, } \\
\text { mont }\end{array} \\
\text { +RAI }\end{array}$} \\
\hline & +RAl & -RAI & + RAl & $-\mathrm{RAl}$ & +RAl & -RAI & +RAI & -RAl & + RAI & RAI & +RAl & -RAI & \\
\hline \multirow{2}{*}{$\begin{array}{l}\text { All cancer } \\
\text { combined }\end{array}$} & 2289 & 2339 & $68.7 \%$ & $72.6 \%$ & $83 \% / 5 \% / 11 \%$ & $85 \% / 8 \%$ & $50 \% / 18 \%$ & $50 \% / 21 \%$ & 62 & 64 & 28 & 26 & 70 \\
\hline & & & & & & $10 \%$ & $/ 17 \%$ & $/ 16 \%$ & & & & & \\
\hline \multirow{2}{*}{$\begin{array}{l}\text { Oral Cavity } \\
\text { and Pharynx }\end{array}$} & 56 & 51 & $64.3 \%$ & $64.7 \%$ & $79 \% / 5 \%$ & $78 \% / 12 \% / 10 \%$ & $48 \% / 11 \%$ & $39 \% / 12 \%$ & 58 & 59 & 22 & 24 & 68 \\
\hline & & & & & $/ 16 \%$ & & $/ 7 \%$ & $/ 8 \%$ & & & & & \\
\hline \multirow{2}{*}{$\begin{array}{l}\text { Digestive } \\
\text { System }\end{array}$} & 319 & 356 & $69.0 \%$ & $72.5 \%$ & $78 \% / 8 \%$ & $81 \% / 10 \% / 10 \%$ & $36 \% / 28 \%$ & $34 \% / 32 \%$ & 64 & 65 & 19 & 14 & 73 \\
\hline & & & & & $/ 14 \%$ & & $/ 24 \%$ & $/ 4 \%$ & & & & & \\
\hline \multirow{2}{*}{$\begin{array}{l}\text { Respiratory } \\
\text { System }\end{array}$} & 247 & 254 & $68.8 \%$ & $72.4 \%$ & $82 \% / 5 \%$ & $83 \% / 9 \%$ & $24 \% / 17 \%$ & $24 \% / 24 \%$ & 68 & 66 & 14 & 10 & 68 \\
\hline & & & & & $/ 12 \%$ & $/ 8 \%$ & $/ 52 \%$ & $/ 48 \%$ & & & & & \\
\hline \multirow[t]{2}{*}{ Skin } & 138 & 137 & $63.0 \%$ & $67.2 \%$ & $96 \% / 1 \%$ & $96 \% / 1 \%$ & $76 \% / 9 \%$ & $78 \% / 11 \%$ & 56 & 64 & 35 & 31 & 65 \\
\hline & & & & & $/ 4 \%$ & $/ 2 \%$ & $/ 3 \%$ & $/ 1 \%$ & & & & & \\
\hline \multirow[t]{2}{*}{ Breast } & 547 & 574 & $99.5 \%$ & $99.8 \%$ & $80 \% / 5 \%$ & $82 \% / 10 \% / 8 \%$ & $65 \% / 30 \%$ & $66 \% / 30 \%$ & 58 & 61 & 35 & 34 & 73 \\
\hline & & & & & $/ 15 \%$ & & $/ 4 \%$ & $/ 3 \%$ & & & & & \\
\hline \multirow{2}{*}{$\begin{array}{l}\text { Female } \\
\text { Genital } \\
\text { System }\end{array}$} & 179 & 206 & $100.0 \%$ & $100.0 \%$ & $83 \% / 7 \%$ & $82 \% / 5 \%$ & $61 \% / 16 \%$ & $51 \% / 23 \%$ & 60 & 62 & 29 & 26 & 66 \\
\hline & & & & & $/ 10 \%$ & $/ 12 \%$ & $/ 16 \%$ & $/ 21 \%$ & & & & & \\
\hline \multirow{2}{*}{$\begin{array}{l}\text { Male Genital } \\
\text { System }\end{array}$} & 237 & 233 & $0.0 \%$ & $0.0 \%$ & $84 \% / 7 \%$ & $88 \% / 9 \%$ & $79 \% / 14 \%$ & $82 \% / 12 \%$ & 65 & 66 & 38 & 50 & 70 \\
\hline & & & & & $19 \%$ & $/ 3 \%$ & $/ 3 \%$ & $/ 2 \%$ & & & & & \\
\hline \multirow{2}{*}{$\begin{array}{l}\text { Urinary } \\
\text { System }\end{array}$} & 194 & 191 & $43.3 \%$ & $57.6 \%$ & $89 \% / 3 \%$ & $90 \% / 5 \%$ & $55 \% / 12 \%$ & $56 \% / 9 \%$ & 64 & 67 & 30 & 31 & 71 \\
\hline & & & & & $/ 8 \%$ & $/ 6 \%$ & $/ 10 \%$ & $/ 8 \%$ & & & & & \\
\hline \multirow{2}{*}{$\begin{array}{l}\text { Nervous } \\
\text { System }\end{array}$} & 30 & 36 & $80.0 \%$ & $69.4 \%$ & $87 \% / 7 \%$ & $94 \% / 3 \%$ & $73 \% / 20 \%$ & $86 \% / 8 \%$ & 57 & 60 & 15 & 12 & 55 \\
\hline & & & & & $/ 7 \%$ & $10 \%$ & $/ 3 \%$ & $10 \%$ & & & & & \\
\hline \multirow{2}{*}{$\begin{array}{l}\text { Hematologic } \\
\text { System }\end{array}$} & 261 & 215 & $65.1 \%$ & $65.6 \%$ & $84 \% / 4 \%$ & $87 \% / 7 \%$ & NA & NA & 63 & 66 & 27 & 23 & 65 \\
\hline & & & & & $/ 11 \%$ & $/ 4 \%$ & & & & & & & \\
\hline
\end{tabular}

\section{Relative Risk Of Developing Spms Associated With Rai Treatment}

To investigate how much the RAI treatment attribute to the increased risk of SPMs development, we assessed the crude and adjusted RR of SPMs associated with RAl treatment (Fig. 1 and Table S2). The significant increased RR was only seen for hematologic cancers $(\mathrm{RR}=1.25,95 \% \mathrm{Cl}$ : $1.05-1.50 ; P=0.015)$, and it became more significant after adjusting with age at DTC diagnosis, gender and year of DTC diagnosis (RR $=1.36,95 \% \mathrm{Cl}: 1.13-1.63 ; P=0.001)$. Adjustment for age at DTC diagnosis, gender and year of DTC diagnosis have a small effect on the RR estimates, generally increasing the risks (Fig. 1 and Table S2). The crude RR for all cancer combined SPMs is 1.01 (95\% Cl:0.95-1.07, $P=0.749)$, and increased to $1.10(95 \% \mathrm{Cl}: 1.03-1.17, P=0.003)$ after adjustment, which become statistically significant (Fig. 1 and Table S2).

After defining a latency time of two years between DTC diagnosis and the SPM development, there were an estimated 11 excess SPMs for all cancer combined that could be related to RAI treatment in our analysis (Fig. 1). The attributable risk of RAl treatment for SPMs development was only $0.9 \%(95 \% \mathrm{Cl}$ : $-4.7 \%-6.5 \%)$, indicating the risk of SPMs attributable to RAl treatment in DTC survivors is low. This proportion was relatively high in patients developed SPMs in hematologic system and oral cavity and pharynx system, for which $20.1 \%$ and $11.7 \%$ SPMs could be related to RAI treatment, respectively (Fig. 1 ). This is consistent with other studies reporting RAl is more likely to induce salivary gland malignancies and leukemia ${ }^{5-6,12}$.

We additionally assessed effect modification by age, gender and latency time between the diagnosis of DTC and SPM. The RRs of SPMs development associated with RAI treatment gradually increase with the age at DTC diagnosis, although the significant increase was only seen in patients with their DTC diagnosed between $60-74 y$ rs ( $R R=1.17,95 \% \mathrm{Cl}: 1.05-1.30, P=0.004$ ) (Table 3). By contrast, the RRs for hematologic SPMs are significantly increased in all age subgroups, except patients with DTC diagnosed older than 75yrs (Table 3). Both genders were not at the increased risk of all cancer combined SPMs associated with RAI treatment, but females receiving RAl treatment had an increased risk of developing hematologic cancer compared to those did not receive RAI (RR $=1.31,95 \% \mathrm{Cl}: 1.05-1.64, P=0.016)$. The RRs of SPMs relative to RAI treatment were significantly elevated in the first 5 years after DTC diagnosis (all 
cancer combined: $\mathrm{RR}=1.11,95 \% \mathrm{Cl}: 1.01-1.22, P=0.025$; hematologic cancers: $\mathrm{RR}=1.83,95 \% \mathrm{Cl}: 1.14-2.94, P=0.012)$ and gradually decrease with increasing time since DTC diagnosis (Table 3).

Table 3

Relative risk of all SPMs or hematologic SPMs for RAl therapy by different stratification.

\begin{tabular}{|lllll|}
\hline \multicolumn{4}{|c|}{ All cancer combined } & \multicolumn{3}{l|}{ Hematologic SPMs } \\
\hline Stratified by diagnosed age & $\mathrm{RR}(95 \% \mathrm{Cl})$ & $P$ value & $\mathrm{RR}(95 \% \mathrm{Cl})$ & $P$ value \\
\hline$<$ 45yrs & $1.05(0.92-1.21)$ & 0.454 & $2.17(1.08-4.38)$ & 0.035 \\
\hline 45-59yrs & $1.08(0.99-1.19)$ & 0.094 & $1.50(1.06-2.10)$ & 0.02 \\
\hline 60-74yrs & $1.17(1.05-1.30)$ & 0.004 & $1.70(1.29-2.25)$ & 0.000 \\
\hline$>=75 y r s$ & $1.18(0.96-1.46)$ & 0.123 & $1.04(0.69-1.58)$ & 0.832 \\
\hline Stratified by gender & & & & \\
\hline female & $1.01(0.94-1.08)$ & 0.816 & $1.31(1.05-1.64)$ & 0.016 \\
\hline male & $0.94(0.85-1.05)$ & 0.303 & $1.04(0.76-1.41)$ & 0.814 \\
\hline Stratified by latency time & & & & \\
\hline$<$ 5yrs & $1.11(1.01-1.22)$ & 0.025 & $1.83(1.14-2.94)$ & 0.012 \\
\hline 5-10yrs & $1.03(0.94-1.13)$ & 0.536 & $1.13(0.85-1.50)$ & 0.413 \\
\hline 10-15yrs & $0.88(0.76-1.02)$ & 0.086 & $1.19(0.88-1.62)$ & 0.266 \\
\hline$>=15 y r s$ & $0.75(0.43-1.33)$ & 0.325 & $0.97(0.56-1.67)$ & 0.898 \\
\hline
\end{tabular}

\section{Comparison of SPMs between RAl-treated and non RAI treated DTC survivors}

The features and outcome are overally comparable in RAI + and RAl- patients (Tables 2 and 4). The descriptive characteristics of SPMs between two groups of patients are presented in Table 2. Few exceptions include: a longer follow-up time were seen in RAI + patients developing SPMs of skin and in RAI- treated patients developing SPMs of male genital system; and a lower mortality in RAl treated patients developing SPMs of digestive system. DTC survivors treated with RAI tend to have a lower overall mortality and disease specific mortality (death caused by SPM), although no statistically significance (Table 4).

Table 4

The mortality of DTC survivors developing SPMs by different sites.

\begin{tabular}{|lllllll|}
\hline & \multicolumn{2}{c}{ overall mortality } & & \multicolumn{3}{c|}{ disease specific mortality } \\
\hline & with RAl & no RAl & $P$ value & with RAl & no RAl & $P$ value \\
\hline All cancer combined & $25.5 \%$ & $28.0 \%$ & 0.001 & $16.4 \%$ & $18.3 \%$ & 0.081 \\
\hline Oral Cavity and Pharynx & $26.8 \%$ & $23.5 \%$ & 0.008 & $7.1 \%$ & $3.9 \%$ & 0.681 \\
\hline Digestive System & $39.5 \%$ & $47.2 \%$ & 0.052 & $32.3 \%$ & $36.8 \%$ & 0.225 \\
\hline Respiratory System & $62.3 \%$ & $61.0 \%$ & 0.783 & $47.8 \%$ & $49.2 \%$ & 0.789 \\
\hline Skin & $12.3 \%$ & $11.7 \%$ & 1.000 & $5.1 \%$ & $2.9 \%$ & 0.54 \\
\hline Breast & $9.9 \%$ & $11.0 \%$ & 0.559 & $4.8 \%$ & $5.9 \%$ & 0.427 \\
\hline Female Genital System & $20.1 \%$ & $22.8 \%$ & 0.537 & $14.5 \%$ & $19.4 \%$ & 0.224 \\
\hline Male Genital System & $8.4 \%$ & $9.0 \%$ & 0.871 & $3.4 \%$ & $3.4 \%$ & 1.000 \\
\hline Urinary System & $17.5 \%$ & $19.9 \%$ & 0.602 & $10.3 \%$ & $8.9 \%$ & 0.73 \\
\hline Nervous System & $63.3 \%$ & $66.7 \%$ & 0.801 & $60.0 \%$ & $63.9 \%$ & 0.802 \\
\hline Hematopoietic System & $25.7 \%$ & $29.3 \%$ & 0.409 & $17.2 \%$ & $20.9 \%$ & 0.347 \\
\hline
\end{tabular}

\section{Discussion}

As the good prognosis of DTC, developing a SPM is probably the greatest concern in DTC survivors ${ }^{16}$. Indeed, SPM has been reported as a major cause of mortality and serious morbidity among DTC survivors. Compared to the general population, DTC survivors have a $10 \%-30 \%$ higher risk to develop a SPM ${ }^{5-8}$, due to the genetic predisposition, environmental factors, lifestyle, and the cancer treatment they received. Regarding to the cancer treatment, RAI is commonly used in DTC treatment for three purposes: 1) RAI remnant ablation to facilitate detection of recurrent disease in the surveillance with serum thyroglobulin; 2) RAl adjuvant therapy to destroy suspected residual disease; 3) RAl therapy to treat persistent disease ${ }^{9,17}$. Many evidences have shown that RAl can decrease 
the metastasis and improve the survival of DTCs patients ${ }^{18-20}$. For low- and intermediate-risk patients, RAl treatment is gradually questioned in the recent few years, as some studies indicated these patients have relative good prognosis, but will be risked to its carcinogenic effects if they receive RAI treatment ${ }^{6-8,12,21}$. However, extensive oppositions existed ${ }^{22-25}$. Considerable arguments about the balance between benefits and harms, as well as the quality of patient care, were generated and widely spread, especially in the nuclear medicine community $22-25$.

The risk of SPMs development associated with RAI in DTCs survivors have been investigated and debated for decades ${ }^{5-8,12,26}$. Many studies presented their evaluations in a way may be easily understood by statisticians, but not the majority of clinical physicians who will read these statistics with the goal of weighting the pros and cons of RAl treatment in their patients. Therefore, in this study, we comprehensively analyzed the risk associated with RAl, and compared the clinical features of SPMs as well as the mortality of RAI + and RAl- treated patients. More specifically, we estimated the proportion of SPMs risk directly associated with RAl, which is for the first time quantitatively showing the absolute risk of RAl in inducing SPMs. These data can be more easily and intuitively interpreted by physicians and patients. Our main findings include: 1) The adjusted RR associated with RAI was only significantly increased for SPMs of hematologic systems; 2 ) Only $0.9 \%$ of all cancer combined SPMs are estimated to be attributed to RAI treatment; the proportion is relatively high in patients developing SPMs in hematologic systems and oral cavity and pharynx system ( $20.1 \%$ and $11.7 \%$ respectively);3) The RRs of all cancer combined SPMs associated with RAI generally increased with age at DTC diagnosis and decreased with the latency time; by contrast, the RRs of hematologic SPMs peaked in patients with DTC diagnosed younger than 45yrs, and then decreased with age at DTC diagnosis; 4) The clinical features and mortality are overally comparable between RAI + and RAl- patients.

There is no doubt RAI would associate with a risk of SPM development as its carcinogenesis effect, but the real concern is how much RAI will contribute to this risk. In this study, we estimated that the attributable risk of RAl treatment for all cancer combined SPMs was only $0.9 \%$. Given the relative low incidence of SPMs in DTC survivors (4.4\%) and this small attributable risk proportion of RAI treatment, the absolute risk of developing SPMs associated with RAI treatment in DTC survivors would be low. Hematologic system is the most susceptible system to develop SPMs after RAI treatment, the adjusted RR is 1.36 (95\%Cl:1.13$1.63, \mathrm{P}=0.001$ ) and the attributable risk proportion of RAI treatment is around $20 \%$, which is the highest among all cancers. However, the incidence of hematologic SPMs in all DTC survivors is only $0.46 \%$, indicating the low absolute number. In addition, there is no way to exclude the effect of thyrotoxicosis on the hematologic SPMs development. RAI treated patients usually are in iatrogenic subclinical thyrotoxicosis, which has been reported as an independent risk factor for leukemia ${ }^{23,27}$. Taken together with these factors, we think both clinicians and patients should be rational about the risk associated with RAl in inducing hematologic SPMs. Clinical features are comparable between RAI + and RAl- patients. The overall mortalities and SPM specific mortalities tend to be lower in RAI treated patients, although are not significant different. We think this probably because RAI treated patients tend to have more frequent surveillances or are more likely to change their lifestyle due to their more advanced tumors.

The main limitation of the SEER data is lacking the amounts of administered activities of RAl, therefore, it is not possible to determine the dose-response effect of RAl in this study. Some studies with available information observed an increased leukemia risk associated with RAl, but only with a dosage higher than $100 \mathrm{mCi}$ or even $150 \mathrm{mCi}^{12,21}$. This means only a small percentage of patients, who accept RAl activity that above the most commonly used $50-100 \mathrm{mCi}$, should be concern of this increased risk. However, in the other hand, patients receiving this high amount of dosage usually have advanced tumors in which RAl has shown survival advantage ${ }^{9}$. Therefore, it is critical to weight the benefits and harms of RAl treatment as well as the dosage of RAl in each individual DTC survivors in clinical practice.

In summary, in this population based data analysis, we found only for SPMs of hematologic SPMs, RAl treatment is associated with an increased RRs and accounts for a relative high attributable risk proportion of developing SPMs. For all cancer combined SPMs, a very low proportion is associated with RAI treatment. In consideration of the low incidence of SPMs in all DTC survivors, the absolute number of SPMs in DTC patients would be small, including hematologic SPMs. Tumor features and the mortality of RAI + and RAl- patients are comparable. Taken all these together, we think it is important to provide the most careful assessment of risks and benefits of RAI to each individual patient in clinical practice, but should not be panicked by the potential risk of SPMs.

\section{Declarations}

\section{Ethics approval and consent to participate}

This article does not contain any studies with human participants or animals performed by any of the authors, thus there is no compliance with ethical standard.

\section{Consent for publication}

Written informed consent for publication was obtained from all authors.

\section{Funding}

This work is supported by the National Natural Science Fund (grant number 81974269, and 81901162).

\section{Authors' contributions}

X.M. and X.Y. extracted and analyzed the data, prepared the figures. X.M. and F.F. prepared the figures and tables. W.C. and H.W. conducted the project and wrote the manuscript. All authors reviewed the manuscript.

\section{Competing interests}


The authors declare no competing interests.

\section{Availability of data and materials}

The datasets analyzed during the current study available from the corresponding

author on reasonable request.

\section{Acknowledgements}

We thank Xiaopei Shen (Fujian Medical University, China) for providing suggestions for statistics, and Chenglai Fu (Tianjin Medical University, China) for manuscript editing.

\section{References}

1. Surveillance E, Results E: (SEER) Program (www.seer.cancer.gov) Research Data (1973-2014), National Cancer Institute, DCCPS, Surveillance Research Program, Surveillance Systems Branch, released April 2017, based on the November 2016 submission.

2. Veiga LH, Neta G, Aschebrook-Kilfoy B, Ron E, Devesa SS. Thyroid cancer incidence patterns in Sao Paulo, Brazil, and the U.S. SEER program, 1997-2008. Thyroid. 2013;23(6):748-757.

3. Gilliland FD, Hunt WC, Morris DM, Key CR. Prognostic factors for thyroid carcinoma. A population-based study of 15,698 cases from the Surveillance, Epidemiology and End Results (SEER) program 1973-1991. Cancer. 1997;79(3):564-573.

4. Lau BJ, Goldfarb M. Age at Primary Malignancy Determines Survival in Adolescent and Young Adults That Develop a Secondary Thyroid Cancer. $J$ Adolesc Young Adult Oncol. 2016;5(2):201-208.

5. Subramanian S, Goldstein DP, Parlea L, et al. Second primary malignancy risk in thyroid cancer survivors: a systematic review and meta-analysis. Thyroid. 2007;17(12):1277-1288.

6. Molenaar RJ, Sidana S, Radivoyevitch T, et al. Risk of Hematologic Malignancies After Radioiodine Treatment of Well-Differentiated Thyroid Cancer. J Clin Oncol. 2018;36(18):1831-1839.

7. Rubino C, de Vathaire F, Dottorini ME, et al. Second primary malignancies in thyroid cancer patients. Br J Cancer. 2003;89(9):1638-1644.

8. Brown AP, Chen J, Hitchcock YJ, Szabo A, Shrieve DC, Tward JD. The risk of second primary malignancies up to three decades after the treatment of differentiated thyroid cancer. J Clin Endocrinol Metab. 2008;93(2):504-515.

9. Haugen BR, Alexander EK, Bible KC, et al. 2015 American Thyroid Association Management Guidelines for Adult Patients with Thyroid Nodules and Differentiated Thyroid Cancer: The American Thyroid Association Guidelines Task Force on Thyroid Nodules and Differentiated Thyroid Cancer. Thyroid. 2016;26(1):1-133.

10. Jonklaas J, Sarlis NJ, Litofsky D, et al. Outcomes of patients with differentiated thyroid carcinoma following initial therapy. Thyroid. 2006;16(12):12291242. doi:10.1089/thy.2006.16.1229

11. Sawka AM, Thabane L, Parlea L, et al. Second primary malignancy risk after radioactive iodine treatment for thyroid cancer: a systematic review and meta-analysis. Thyroid. 2009;19(5):451-457.

12. Teng CJ, Hu YW, Chen SC, et al. Use of Radioactive lodine for Thyroid Cancer and Risk of Second Primary Malignancy: A Nationwide Population-Based Study. J Natl Cancer Inst. 2015;108(2).

13. Berrington de Gonzalez A, Curtis RE, Kry SF, et al. Proportion of second cancers attributable to radiotherapy treatment in adults: a cohort study in the US SEER cancer registries. Lancet Oncol. 2011;12(4):353-360.

14. Berrington de Gonzalez A, Curtis RE, Gilbert E, et al. Second solid cancers after radiotherapy for breast cancer in SEER cancer registries. Br J Cancer. 2010;102(1):220-226.

15. Cheng W, Shen XP, Xing M. Decreased breast cancer-specific mortality risk in patients with a history of thyroid cancer. PLoS One. 2019;14(10): e0221093.

16. Liou MJ, Tsang NM, Hsueh C, Chao TC, Lin JD. Therapeutic Outcome of Second Primary Malignancies in Patients with Well-Differentiated Thyroid Cancer. Int J Endocrinol. 2016;2016:9570171.

17. Tuttle RM, Ahuja S, Avram AM, et al. Controversies, Consensus, and Collaboration in the Use of 131I Therapy in Differentiated Thyroid Cancer: A Joint Statement from the American Thyroid Association, the European Association of Nuclear Medicine, the Society of Nuclear Medicine and Molecular Imaging, and the European Thyroid Association. Thyroid. 2019;29(4):461-470.

18. Haymart MR, Banerjee M, Stewart AK, Koenig RJ, Birkmeyer JD, Griggs JJ. Use of radioactive iodine for thyroid cancer. JAMA. 2011;306(7):721-728.

19. Ruel E, Thomas S, Dinan M, Perkins JM, Roman SA, Sosa JA. Adjuvant radioactive iodine therapy is associated with improved survival for patients with intermediate-risk papillary thyroid cancer. J Clin Endocrinol Metab. 2015;100(4):1529-1536.

20. Kammori M, Fukumori T, Sugishita Y, Hoshi M, Shimizu K, Yamada T. Radioactive iodine (RAI) therapy for distantly metastatic differentiated thyroid cancer (DTC) in juvenile versus adult patients. Endocr J. 2015;62(12):1067-1075.

21. Seo GH, Cho YY, Chung JH, Kim SW. Increased Risk of Leukemia After Radioactive lodine Therapy in Patients with Thyroid Cancer: A Nationwide, Population-Based Study in Korea. Thyroid. 2015;25(8):927-934.

22. Tulchinsky M, Baum RP, Bennet KG, et al. Well-Founded Recommendations for Radioactive lodine Treatment of Differentiated Thyroid Cancer Require Balanced Study of Benefits and Harms. J Clin Oncol. 2018;36(18):1887-1888. 
23. Greenspan BS. Radioiodine Treatment of Well-Differentiated Thyroid Cancer: Balancing Risks and Benefits. J Clin Oncol. 2018;36(18):1785-1787.

24. Metter D, Phillips WT, Walker RC, Blumhardt R. To Use or Not to Use 131I in Thyroid Cancer. Clin Nucl Med. 2018;43(9):670-671.

25. Verburg FA, Giovanella L, lakovou I, et al. I-131 as adjuvant treatment for differentiated thyroid carcinoma may cause an increase in the incidence of secondary haematological malignancies: an "inconvenient" truth?. Eur J Nucl Med Mol Imaging. 2018;45(13):2247-2249.

26. McLeod DS, Sawka AM, Cooper DS. Controversies in primary treatment of low-risk papillary thyroid cancer. Lancet. 2013;381(9871):1046-1057.

27. Saenger EL, Thoma GE, Tompkins EA. Incidence of leukemia following treatment of hyperthyroidism. Preliminary report of the Cooperative Thyrotoxicosis Therapy Follow-Up Study. JAMA. 1968;205(12):855-862.

\section{Figures}

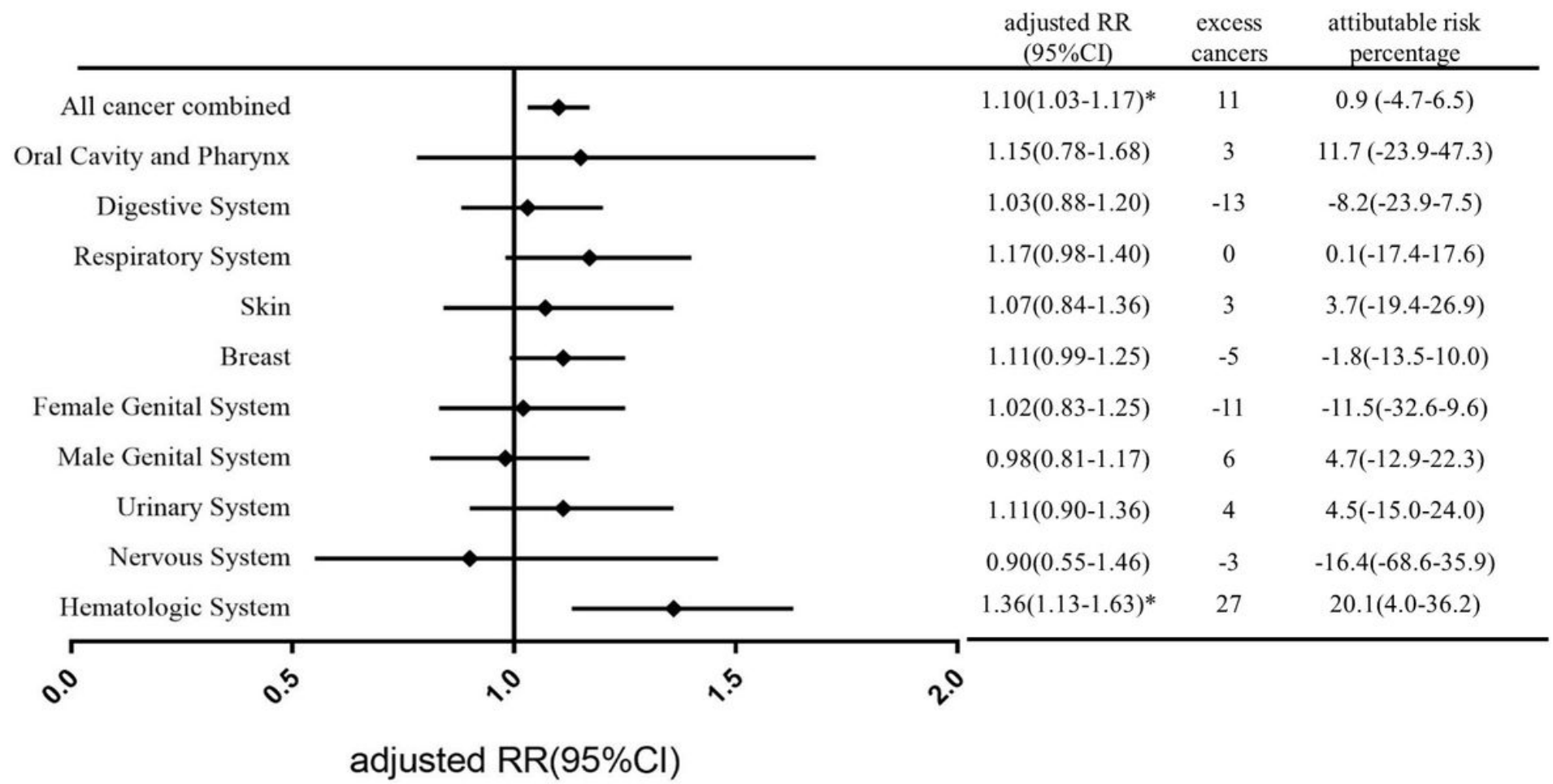

Figure 1

The adjusted relative risk of SPMs, the estimated number of excess cancers and the attributable risk associated with RAI treatment by the site of SPMs. The RR was adjusted with age at DTC diagnosis, gender and year of DTC diagnosis.

\section{Supplementary Files}

This is a list of supplementary files associated with this preprint. Click to download.

- datasupplement01122021.pdf 